\title{
GESTÃO DA OUVIDORIA ORIENTADA POR RESULTADOS
}

Bruno Marques ${ }^{1}$

\section{Resumo}

O Serviço de Limpeza Urbana do Distrito Federal - SLU/DF é uma autarquia, que tem como competência a coleta, transporte, triagem, transbordo, tratamento e destinação final de resíduos sólidos urbanos domiciliares no Distrito Federal. No período de 2015 a 2018, o órgão encontrava-se em evidência por ainda existir, na capital do País, o segundo maior lixão do mundo em operação com catadores, segundo a ISWA (Associação Internacional de Resíduos Sólidos). A continuidade do Lixão da Estrutural também era uma afronta à Lei n 12.305/10 Política Nacional dos Resíduos Sólidos. Para fechar o Lixão, o SLU precisava antes construir o primeiro Aterro Sanitário de Brasília e promover a inclusão dos catadores. Mas os desafios não acabavam por aí: o órgão precisava ainda de reestruturação, revisão dos processos e modernização dos sistemas. Entre todas essas necessidades de mudanças e o usuário do Serviço de Limpeza Urbana estava a Ouvidoria. O diagnóstico realizado pela equipe em 2015 não foi nada favorável e sinalizou alguns alertas. Por conta dessa realidade, a Ouvidoria propôs aos dirigentes do órgão a implantação da metodologia de gestão da área orientada por resultados, visando assegurar a qualidade das informações prestadas aos usuários, a transparência e a melhoria dos serviços prestados. O trabalho, inovador pelo posicionamento da Ouvidoria como unidade consultiva, apresentou vários fatores-chave de sucesso, e com os resultados vieram os reconhecimentos. Entretanto, mais do que prêmios, a Ouvidoria deixa um legado técnico para a equipe, presente na organização das ações, com a valorização interna e, principalmente, com a satisfação dos usuários que acionam o Serviço de Limpeza Urbana.

Palavras-Chave: Ouvidoria. Gestão. Usuário. Resultado. Resíduos. Transparência.

DOI:10.37814/2594-5068.2020v3.p93-106

1 Gestor Público. Pós-Graduado em Auditoria Pública pela Universidade Gama Filho (RJ). Graduado em Administração de Empresas pelo Centro Universitário de Brasília (UniCeub). Ouvidor do Serviço de Limpeza Urbana do Distrito Federal, desde 12.08.2015. (bruno.marques@slu.df.gov.br) 


\section{Abstract}

The Urban Cleaning Service of the Federal District - SLU/DF is a local authority, which is responsible for the collection, transportation, sorting, transhipment, treatment and final disposal of household solid urban waste in the Federal District. From 2015 to 2018 the agency was in evidence because there is still, in the capital of the country, the second largest dump in the world in operation with waste pickers, according to ISWA (International Solid Waste Association). The continuity of the Dump Structural Law was also an affront to Law $n^{\circ} 12.305 / 10-\mathrm{Na}-$ tional Policy on Solid Waste. In order to close the Dump, SLU needed to build the first Brasilia Landfill and promote the inclusion of waste pickers. But the challenges did not end there: the agency still needed restructuring, review of processes and modernization of systems. Among all these changing needs and the Urban Cleaning Service user was the Ombudsman. The diagnosis made by the team in 2015 was not favorable and signaled some alerts. Because of this reality, the Ombudsman's Office proposed to the agency's managers the implementation of the results-oriented area management methodology, aiming to ensure the quality of the information provided to users, the transparency and the improvement of the services provided. The work, groundbreaking by the position of the Ombudsman as an advisory unit, presented several key success factors, and with the results came the acknowledgments. However, more than awards, the Ombudsman leaves a technical legacy for the team, present in the organization of actions, with internal appreciation and, mainly, with the satisfaction of users who operate the Urban Cleaning Service.

Keywords: Ombudsman. Management. User. Result. Waste and Transparency. 


\section{LISTA DE SIGLAS}

5W2H - Plano de Ação, ferramenta de gestão (What, Why, Who, When, Where, How e How much) ABO/DF - Associação Brasileira de Ouvidores/Ombudsman do Distrito Federal

Ascom - Assessoria Especial de Comunicação e Mobilização Social

$\mathrm{BI}$ - Business Intelligence

CGDF - Controladoria-Geral do Distrito Federal

CGU - Controladoria-Geral da União

Codeplan - Companhia de Planejamento do Distrito Federal

Conlurb - Conselho de Usuários da Limpeza Urbana do Distrito Federal

DF - Distrito Federal

Diafi - Diretoria de Administração e Finanças

Diget - Diretoria de Gestão e Modernização Tecnológica

Dilur - Diretoria de Limpeza Urbana

Enap - Escola Nacional de Administração Pública

E-SIC - Sistema Eletrônico do Serviço de Informação ao Cidadão

FAQ - Perguntas e Respostas Frequentes (Frequently Answers and Questions)

GDF - Governo do Distrito Federal

GpR - Gestão para Resultados

IN - Instrução Normativa

ISWA - Associação Internacional de Resíduos Sólidos

Masp - Método de Análise e Solução dos Problemas

OGDF - Ouvidoria-Geral do Distrito Federal

OGU - Ouvidoria-Geral da União

OUV - Sistema de Ouvidoria do Distrito Federal

Ouvir - Assessoria Especial da Ouvidoria do SLU

Paga - Plano Anual de Gestão e Ação

PDCA - Ciclo de Planejamento, Execução, Verificação e Ação

Sigo - Sistema de Gestão de Ouvidoria do Distrito Federal

SLU - Serviço de Limpeza Urbana do Distrito Federal 


\section{INTRODUÇÃO}

Em agosto de 2015, a Diretoria do Serviço de Limpeza Urbana do Distrito Federal necessitou recompor a chefia de várias das suas unidades orgânicas internas, entre elas a Assessoria Especial da Ouvidoria - Ouvir. Ao constatar a situação da infraestrutura, o quadro funcional e as condições de trabalho, o gestor nomeado iniciou um diagnóstico técnico da área para analisar e propor metodologia de trabalho à equipe e à direção do órgão.

A princípio o diagnóstico identificou os seguintes sintomas: infraestrutura inadequada, equipe da Ouvidoria desmotivada, distanciamento da Ouvidoria das demais áreas, fluxo de tratamento por memorando ou malotes, respostas internas divergentes. Após o diagnóstico, a equipe da Ouvidoria realizou reuniões de planejamento e identificou alguns objetivos específicos para os usuários, para a Ouvir e para a autarquia.

Como afirmam BARREIRO, PEREZ, PASSONI (2011), Ouvidoria vai muito além de ser um serviço de atendimento de balcão. A Ouvidoria tem por finalidade garantir a excelência dos processos e da gestão nos órgãos e instituições em que atua, garantindo a organização interna, o trâmite e o tratamento adequado de informações que corroboram para o desempenho institucional e a melhoria da qualidade dos serviços como um todo.

Sendo assim, foi proposta a metodologia de Gestão Orientada por Resultados, criada por Peter Drucker, que consiste no planejamento amplo das ações a serem desenvolvidas pela área. É uma metodologia elaborada com o intuito de sistematizar as atividades necessárias à concretização dos objetivos da equipe e do órgão. Envolve recursos humanos, financeiros, materiais, tecnológicos, objetivos, ações, projetos e metas.

\section{DESENVOLVIMENTO}

\subsection{Diagnóstico}

Em parceria com o Núcleo de Normatização da Diretoria Técnica, a Ouvidoria realizou o diagnóstico, em setembro de 2015, com as unidades operacionais do SLU (unidades de gestão nas cidades-satélites), do atendimento prestado às demandas dos usuários do Serviço de Limpeza Urbana.

Os principais problemas encontrados foram: falhas na comunicação interna; morosidade na execução dos serviços; elevado encaminhamento de manifestações duplicadas; recebimento de demandas que não são de competências do órgão; extravio de manifestações e/ou respostas; processo burocrático e moroso no trâmite e tratamento das demandas; ausência de dados nas manifestações (endereço, divergência entre o assunto e a manifestação); emissão de respostas evasivas e desvinculadas das demandas dos usuários; equipe da Ouvidoria desmotivada; informações da transparência ativa inexistente ou desatualizada; e a Ouvidoria tinha baixa importância para o órgão.

Além das atribuições da Ouvidoria, outros problemas também foram constatados: site e FAQ 
(Perguntas e Respostas Frequentes - Frequently Asked Questions) desatualizados e com erros; informações divergentes entre as áreas internas; ausência de controles, entre outros.

A Ouvidoria do SLU também aproveitou, para o diagnóstico, a base de informação existente nas manifestações e os depoimentos gerados no projeto Ouvidoria Junto, de 2015, em todas as Administrações Regionais.

Consequências aos usuários do Serviço de Limpeza Urbana: respostas inadequadas, divergentes, atrasadas; informações ausentes ou desatualizadas sobre as rotas de coleta no site; dificuldade de compreensão dos serviços prestados pela autarquia; ambiente de atendimento presencial inadequado e ausência de representatividade social.

\subsection{Planejamento}

Em dezembro de 2015, a equipe da Ouvidoria realizou várias reuniões de planejamento com o intuito de definir a metodologia de trabalho para os anos seguintes 2015-2018 (curto, médio e longo prazos).

Tomando ciência das competências regimentais, legais e do resultado do diagnóstico, a equipe da Ouvidoria definiu alguns objetivos específicos para os usuários, para o setor e para a autarquia. São eles: melhoria no atendimento prestado aos usuários do Serviço de Limpeza Urbana; melhoria na transparência ativa e passiva do órgão; melhoria nas condições (infraestrutura), divulgação e reconhecimento do trabalho da Ouvidoria do SLU; e contribuição para a melhoria dos produtos e serviços do órgão.

Diante desses desafios, a equipe optou pela metodologia de Gestão Orientada por Resultados ou Gestão por Resultados (GpR). O termo "Gestão por Resultados" foi usado pela primeira vez pelo austríaco Peter Drucker, em 1954, no livro The Practice of Management. A Gestão por Resultados visa a transformar os objetivos em resultados a serem alcançados. Portanto, é a gestão do fluxo dos procedimentos, atividades e ações necessárias para o alcance dos propósitos almejados.

Nesse pensamento, segundo GOMES (2009), pode-se entender que a gestão por resultados é desenvolvida por meio de um ciclo que começa com o estabelecimento dos objetivos almejados, traduzindo-os para resultados desejados; seguido do monitoramento e da avaliação do desempenho da organização a partir do alcance desses resultados; que retroalimenta o sistema de gestão, propiciando ações corretivas decorrentes dessa avaliação.

Diante do exposto, a Ouvidoria do SLU utilizou as seguintes fases para a sua Gestão por Resultados expressas no infográfico a seguir: 

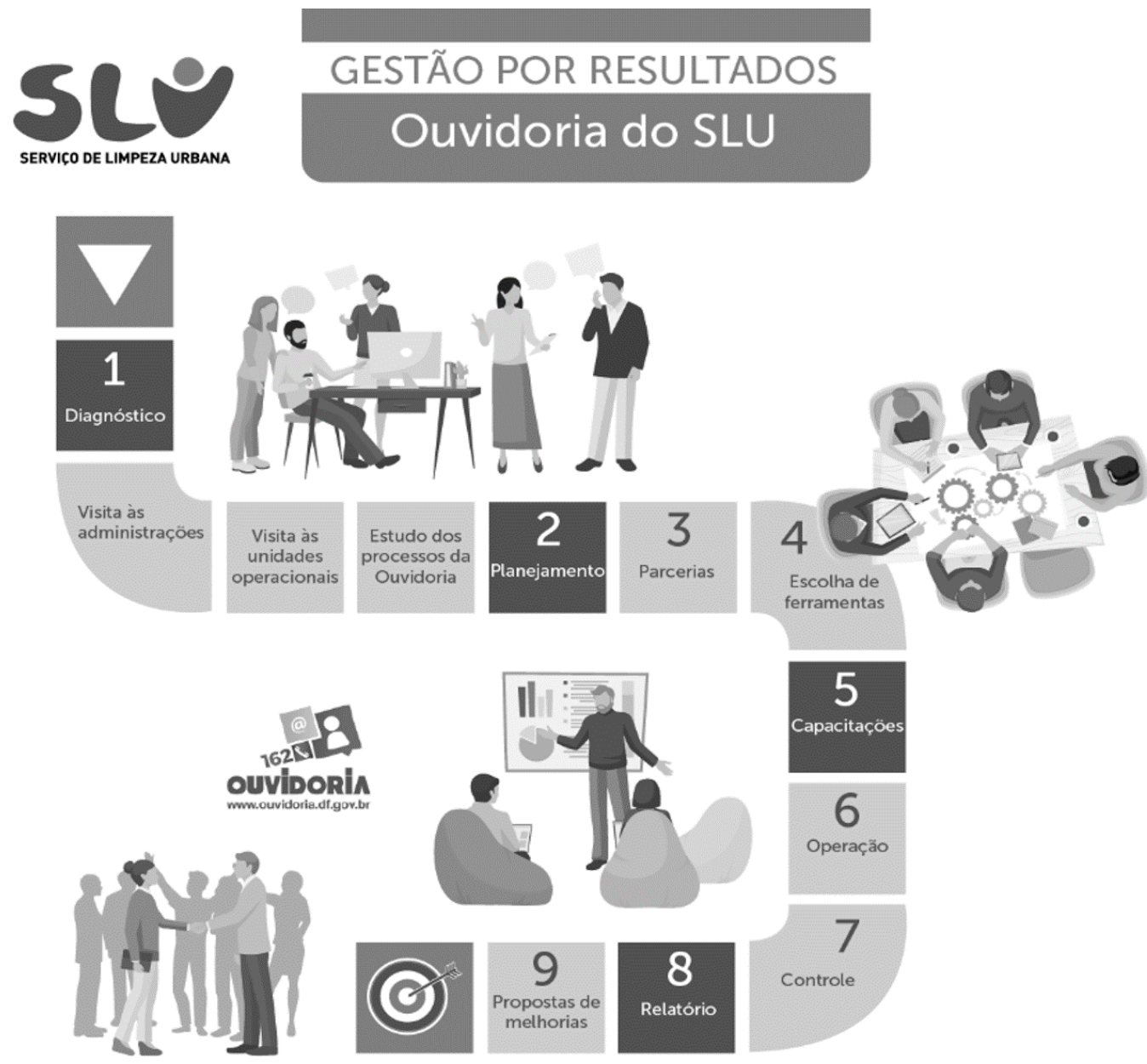

Observe que, até aqui, mesmo que não haja resultados, é possivel captar mudanças. Entre os exemplos, a área consegue entender suas competências, atribuições e responsabilidades, identificou os seus gargalos, definiu uma metodologia de trabalho e, o mais importante, definiu objetivos futuros desejados.

Com a metodologia definida, a Ouvidoria iniciou a produção do Plano Anual de Gestão e Ação (Paga), objetivando o cumprimento das ações de médio e curto prazos. Para a produção do plano de ação foi utilizada a técnica $5 \mathrm{~W} 2 \mathrm{H}$, que consiste na definição dos seguintes parâmetros: o quê, quem faz, como faz, quais os recursos utilizados, até quando, por quê, quem cobra e qual o status. $\mathrm{O}$ método $5 \mathrm{~W} 2 \mathrm{H}$ foi desenvolvido pelo professor Joseph M. Juran, no livro Quality Planning and Analysis, de 1980, e aplicado na indústria automobilística do Japão. No aspecto do planejamento, o grande desafio é transformar os resultados desejados em ações, projetos, metas e indicadores. Por isso, o plano de ação é uma espécie de guia, traçando o caminho e a forma de acompanhamento das ações elencadas.

O Paga definiu as metas para cada exercício dentro da metodologia de Gestão por Resultados $(G p R)$. Nesse momento foram definidos alguns indicadores a serem seguidos para o protagonismo da área no órgão. No site da Ouvidoria do SLU é possível visualizar todos os Pagas e os relatórios de gestão e informação da Ouvidoria. 


\subsection{Parcerias}

Sabe-se que um dos fatores para alavancar o sucesso em qualquer projeto está relacionado às parcerias firmadas, que geram benefícios mútuos. A Ouvidoria buscou o apoio e a troca de experiências com outras unidades para alcançar objetivos (resultados) em comum. $O$ trabalho voltado ao usuário oferecido pela Ouvidoria requer eficácia e eficiência do início da demanda solicitada até a resposta definitiva.

Para tanto, é necessário o empenho em conjunto dos diretores, colaboradores da Ouvidoria e, por fim, dos servidores das áreas técnicas do SLU, para que o resultado seja o mais positivo possível para o usuário.

Parceiros internos: A Presidência, a Diretoria e gerentes de limpeza (área operacional), que acolheram e apoiaram as mudanças propostas pela Ouvidoria. Sem o apoio interno seria muito difícil a manutenção da metodologia proposta, a mudança na transparência e no atendimento às demandas dos usuários. A Diretoria de Limpeza Urbana (Dilur) deu grandes contribuições com os resultados e com o atendimento das demandas da Ouvidoria, tendo em vista que essa área atende $90 \%$ das manifestações e $50 \%$ dos pedidos de acesso à informação. A Diretoria de Administração e Finanças (Diafi) apoia a Ouvidoria na realização das palestras e capacitações dentro dos programas do órgão. A Assessoria de Comunicação e Mobilização Social (Ascom) deu apoio incondicional na publicação de matérias, confecção de material, revisão de texto, colaboração com a Carta de Serviços, entre outras ações. E a Diretoria de Gestão e Modernização Tecnológica (Diget) disponibiliza seus técnicos e os sistemas do órgão para o acompanhamento estratégico das metas/indicadores da Ouvidoria do SLU e atualiza as informações nos sites do órgão.

Parceiros externos: A Companhia de Planejamento do Distrito Federal (Codeplan) contribuiu para a implantação da pesquisa de satisfação dos usuários, para verificação de opinião sobre os serviços prestados pelo SLU. A pesquisa foi conduzida por telefone em uma amostra de 4.088 (quatro mil e oitenta e oito) usuários de todo o Distrito Federal. A Codeplan auxiliou com a metodologia e a aplicação da pesquisa, o que rendeu prêmio de melhores práticas em Ouvidoria aos dois órgãos em 2016. Outra técnica também muito utilizada pela Ouvidoria do SLU foi o benchmarking, que buscou as melhores práticas a fim de agregar conhecimento aos seus processos. $O$ benchmarking é a ação de observar e aprender como instituições semelhantes realizam suas atividades, podendo ser aplicado a qualquer área de atividade organizacional, desde o desenvolvimento estratégico até a operação (WATSON, 1994).

Parceiro de Destaque: A Ouvidoria do SLU faz parte do Sistema de Gestão de Ouvidoria do Distrito Federal (Sigo/DF), sendo uma unidade seccional sujeita à orientação normativa e supervisão do órgão central do sistema, conforme a Lei no 4.896/2012. Trata-se de uma parceria condicionada, pois a Ouvir tem a obrigação de utilizar o sistema proposto pela Ouvidoria-Geral do Distrito Federal. Convém destacar que a Ouvidoria-Geral é um grande referencial técnico e de suporte às capacitações direcionadas, inclusive com seu programa de certificação. 


\subsection{Infraestrutura, ferramentas e sistematização}

A Ouvidoria utilizou o sistema OUV², desenvolvido pela Controladoria-Geral do Distrito Federal (CGDF). Com duas premiações nacionais, o OUV é utilizado por todas as Ouvidorias especializadas no DF: secretarias de Estado, empresas públicas, administrações regionais, autarquias, fundações e demais órgãos que compõem o complexo administratativo do Governo do Distrito Federal - GDF.

Nesse sistema, muito dinâmico e interativo, a manifestação é registrada com detalhes, gerando protocolo que possibilita o acompanhamento da demanda, com prazo limite de atendimento. Ao final, o usuário do Serviço de Limpeza tem a opção de avaliar a qualidade da execução do serviço prestado.

Além do sistema de tratamento das manifestações, a Ouvidoria também opera o Sistema Eletrônico do Serviço de Informação ao Cidadão (e-SIC). O sistema permite que qualquer pessoa, física ou jurídica, encaminhe pedidos de acesso à informação para órgãos e entidades do Poder Executivo Distrital. Também é possível acompanhar o prazo, o andamento e receber as respostas, além de entrar com recursos e apresentar reclamações pela demora na resposta. $O$ objetivo sempre é facilitar o exercício do direito de acesso à informação pública.

Com a mudança de sede do SLU em fevereiro de 2016, a Ouvidoria ganhou nova estrutura física, com instalações mais confortáveis, propiciando melhores condições de atendimento ao usuário. Sala-escritório exclusiva da Ouvidoria (dividida em dois ambientes, o que facilita os atendimentos presenciais), ar-condicionado, mesas, armários, computadores, telefones, impressora e TV Smart para o acompanhamento das manifestações, metas e indicadores.

Para atender ao Decreto Distrital no 36.419/2015 e à Resolução Adasa n 21/2016, o Serviço de Limpeza Urbana elaborou a Carta de Serviços ao Usuários da Limpeza Urbana, que é o instrumento para informar os usuários sobre a relação dos serviços ofertados pelo órgão, orientando a utilização e cobrando a devida regularidade, pontualidade e qualidade. A intenção é torná-lo, além de um guia de informação, um compromisso de fiel execução.

A implantação da Carta de Serviços pelos órgãos públicos pressupõe transformações institucionais, sustentado o princípio de que as entidades devem atuar buscando satisfazer as necessidades da sociedade e manter os padrões de desempenho estabelecidos nas normas legais, regulamentares e de regulação.

Outra ferramenta de atendimento implantada foi o Perguntas e Respostas Frequentes (FAQ), com base no banco perguntas e respostas emitidas por diversas áreas internas. A ferramenta está disponível no site do SLU. O intuito é tornar acessível ao usuário as respostas às demandas mais frequentes relativas à prestação dos serviços pelo órgão. Ainda assim, o atendimento direto ao usuário continua sendo prestado normalmente, sendo esse apenas um auxílio ao usuário internauta. O FAQ foi dividido em palavras-chave, ou seja, temas que ajudam o usuário a localizar a respectiva dúvida de forma mais rápida.

2 Ver OUV em Referências. 


\subsection{Capacitações e certificações}

O SLU não dispõe de centro de capacitação específico, ficando o treinamento de servidores a cargo da Escola de Governo, da Ouvidoria-Geral e de entidades externas. Entretanto, o SLU possui um programa de ciclo de palestras chamado "Vem Saber", de capacitação para toda a autarquia.

Conforme demonstrado nas parcerias, a Ouvidoria precisa de alianças internas para a construção da ponte entre os dois lados (SLU-usuário). Por isso, mesmo no Dia do Ouvidor, é a Ouvidoria que presenteia as unidades internas com o projeto Amigos da Ouvidoria, que consagra com reconhecimentos as unidades orgânicas internas de melhor desempenho nos atendimentos. Entre os critérios, as manifestações de Ouvidoria - parâmetros de cálculo que levam em consideração a resolutividade da área (peso 1), o prazo médio de atendimento das manifestações (peso 2) e a avaliação do usuário (peso 3). Pedidos de acesso à informação - o parâmetro de cálculo levou em consideração a resolutividade da área (peso 1) e o prazo médio.

Como forma de aprendizagem, a Ouvidoria realiza na intranet do órgão um jogo "Quiz" que, na verdade, é um teste de conhecimento sobre a Ouvidoria. A realização do $1^{\circ}$ Quiz sobre a Ouvidoria na intranet do SLU teve a participação de $15 \%$ dos logins da autarquia. A segunda versão será publicada brevemente. O objetivo principal é disseminar conhecimento sobre Ouvidorias de forma descontraída e por meio de competição sadia. De acordo com o Oxford English Dictionary, a palavra quiz é usada com o significado de "enigma, pergunta" desde 1843. A etimologia é incerta: alguns dizem que vem do pronome interrogativo latino qui (quem?).

A Ouvir também concentrou seus esforços na capacitação dos membros da própria equipe em atividades da OGDF, congressos e cursos externos, buscando sempre a obtenção de certificações. Em 2016, foram 104 horas de capacitações acumuladas pela equipe. No ano seguinte, foram 317 horas; 124 horas em 2018; e, até junho de 2019, a equipe já acumulava 300 horas de capacitação.

O Ouvidor possui as seguintes certificações: Certificação de Ouvidores, pela Associação Brasileira de Ouvidores/Ombusman ABO/Nacional (20 horas, presencial); Certificação pela Controladoria-Geral do Distrito Federal - CGDF, pela Escola de Governo do Distrito Federal (96 horas, presencial); e Certificação pela Controladoria-Geral da União - CGU, pela Escola Nacional de Administração Pública - Enap (120 horas, a distância).

\subsection{Operação}

Como demonstrado no diagnóstico, era imprescindível a identificação das competências, das atribuições e dos processos/subprocessos que estavam definidos regimentalmente para a Ouvidoria do SLU.

A organização dos trabalhos era crucial para alcance dos resultados propostos (GpR). A Ouvir começou pelo check-list, que é a padronização do formato das respostas preliminares, encaminhamento e respostas definitivas, com linguagem mais cidadã.

Posteriormente todos os processos foram mapeados utilizando a técnica Masp (Método de Análise e Solução dos Problemas), que é uma forma estruturada de analisar e solucionar problemas da 
rotina diária das organizações, também conhecida como Movimento da Qualidade Total no Japão.

Trata-se de um desdobramento do método gerencial intitulado Ciclo PDCA - P (Plan/Planejamento), D (Do/Execução), C (Check/Verificação) e A (Action/Ação), idealizado por Shewhart e divulgado por E. Deming 3 .

Com esse trabalho a Ouvidoria do SLU desenvolveu o Manual Técnico Operacional de Atendimento como ferramenta de padronização e gestão, utilizando como referência o manual da Ouvidoria-Geral do Distrito Federal.

O trabalho resultou no desenvolvimento da política interna de Ouvidoria divulgada recentemente no Diário Oficial do Distrito Federal (In SLU n 010/2019). A Instrução dispõe sobre os compromissos com o atendimento, prioridade no tratamento, procedimentos internos e o horário de atendimento da Ouvidoria do SLU/DF.

De modo igual, outra possível ação que pode ter mudado a dinâmica do trabalho da Ouvidoria do SLU foi a abertura do sistema OUV para as Diretorias (áreas de gestão) e para as gerências de limpezas (áreas operacionais), com perfil parametrizado pelo sistema para usuários de Unidades Finalísticas, visando à tempestividade das respostas aos usuários, o envolvimento de todos no tratamento das demandas do usuário e o fortalecimento da política de Ouvidoria no órgão.

\subsection{Controle}

O processo de monitoramento levou em conta a análise objetiva dos resultados obtidos, das informações da equipe, a percepção dos parceiros e dos usuários. A Ouvidoria utiliza várias fontes de dados, sendo as principais as geradas pelos sistemas da Ouvidoria-Geral (OUV e e-SIC).

Todos esses dados são consolidados em um banco que alimenta o Business Intelligence (BI) do SLU, ferramenta de inteligência que facilita a interpretação dos dados e identifica as áreas que merecem atenção. A ferramenta é de uso exclusivamente interno da autarquia.

\subsection{Relatórios}

No caminho da gestão orientada por resultado, a gestão da informação é um componente básico. Conforme o Dicionário Aurélio, "relatório" é derivado do verbo "relatar", é a exposição, oral ou escrita, que se caracteriza por conter uma descrição detalhada dos aspectos mais importantes, eventos ou ações, de alguma coisa.

Em julho de 2016, a Ouvidoria do SLU apresenta o seu primeiro relatório analítico com a evolução dos resultados e indicadores. Os relatórios atuam como ferramenta de controle para a concretização dos resultados obtidos pelo SLU e por sua Ouvidoria. Todos os resultados desse modelo de gestão estão registrados da seguinte forma:

Relatórios mensais: quantitativos.

3 Texto adaptado da apostila de treinamento da Escola Nacional de Administração Pública - ENAP. 
Relatórios trimestrais: analíticos (obrigatórios).

Relatórios semestral e anual: analíticos, prestação de contas das ações, apresentação de resultados, metas, indicadores, recomendações, ações externas/internas e avaliações cidadãs, entre outras informações.

A Ouvidoria tem a preocupação de construir relatórios com aspecto visual agradável, conciso e com linguagem cidadã, tendo em vista que o relatório tem o objetivo de prestação de contas e transparência aos gestores do SLU, como também ao cidadão, aos usuários do SLU, aos orgãos fiscalizadores e aos apoiadores/parceiros da autarquia.

Em 2018, a Ouvidoria do SLU buscou desenvolver relatórios dinâmicos, segmentados ou específicos para cada unidade orgânica. A adoção da presente prática visa estimular a leitura e o uso das informações pelas áreas técnicas internas, uma vez que são destacados apenas os dados sob sua responsabilidade.

\subsection{Propostas de melhorias}

O último passo da metodologia de Gestão por Resultados da Ouvidoria é a proposição de melhorias para a otimização dos processos, produtos e serviços ofertados pela autarquia (recomendação).

A Assessoria Especial da Ouvidoria do Serviço de Limpeza Urbana - SLU é uma unidade orgânica de "controle", que tem como competência prezar pela elevação da eficiência, da melhoria do atendimento ao usuário, da transparência e o aprimoramento e a racionalização administrativa.

Diante disso, passou a utilizar as recomendações de melhorias, visando à qualificação dos produtos/serviços. Em seguida, alguns dos aspectos abordados pela Ouvidoria que obtiveram resultados favoráveis aos usuários:

O barulho na coleta (convencional e seletiva) - Em 2016, o barulho era o terceiro assunto com mais reclamações no SLU. A Ouvidoria levou o problema à direção do órgão, que iniciou estudos de adaptações a serem feitas em toda a frota de caminhões compactadores das empresas contratadas, com o objetivo de diminuir a geração de ruído. O volume de ruído atingiu 93 decibéis nos testes com caminhão e contêiner de metal sem adaptação. Já com os veículos adaptados, o ruído atingiu o máximo de 78 decibéis. $E$ com contêiner de plástico obtivemos 63 decibéis. O custo das adaptações ficou a cargo das empresas contratadas. Além das adaptações nos caminhões coletores, a IN $n^{0}$ 114/2016 recomenda adaptações aos condomínios e proprietários de contêineres. As adaptações incluem abafadores ou a substituição dos equipamentos por contêineres de plástico (PEAD) para diminuir o barulho. O barulho nas coletas somava $24 \%$ (vinte e quatro por cento) das manifestações não atendidas e atualmente não aparece entre os dez primeiros serviços mais reclamados.

Perguntas e Respostas Frequentes (FAQ) - De acordo com o diagnóstico da Ouvidoria do SLU, em 2015 o FAQ estava desatualizado, com links quebrados e de difícil navegação. Após os questionamentos da Ouvidoria, foi desenvolvido o novo FAQ do SLU com diversos temas, inclusive assuntos transversais e até mesmo assuntos que não competem ao SLU. Os FAQs conseguem 
solucionar diversas dúvidas comuns de diversos usuários sem o acionamento constante de uma equipe enorme. Quanto mais completo for o $F A Q$, menos dúvidas sobrarão para uma ligação ou um e-mail. Ele potencializa o atendimento, agiliza o processo e economiza recursos.

Conserto de contêiner quebrado por má operação - Conserto de contêiner danificado era o assunto campeão na avaliação negativa dos serviços prestados pelo SLU, com 22\% (vinte e dois por cento) das manifestações não atendidas no $1^{\circ}$ semestre de 2017 . A Ouvidoria propôs, em março de 2017, a revisão do processo, com participação cidadã, principalmente na realização de vistoria (laudo técnico), na coleta do contêiner para o conserto e no ato da entrega.

Obtenção do índice de $100 \%$ de transparência ativa e o reconhecimento do grau de excelência pelo Tribunal de Contas do Distrito Federal, em 2018.

Conversão da transparência passiva em ativa - Em decorrência do aumento dos pedidos de acesso à informação sobre o novo concurso, em janeiro de 2019 foi recomendada ao SLU a conversão das informações de transparência passiva para ativa, o que resultou no desenvolvimento da página específica no site do SLU.

O mais importante nesse processo foi o espaço conquistado pelo SLU, elevando sua importância externa e trazendo uma bagagem de maturidade como Instituição. Com base nas informações recebidas dos usuários via manifestações, pesquisa, pedido de acesso â informação, entre outros, a Ouvidoria consegue identificar tendências, pontos críticos de prestação de serviço e locais que necessitam de atuação da área de orientação ambiental.

\section{CONSIDERAÇÕES FINAIS}

Este trabalho demonstra que existia desvalorização e isolamento da equipe da Ouvidoria do SLU, que atuava sem participação e controle social. Parte da desvalorização se devia ao desconhecimento das atribuições e competências e até mesmo da importância da unidade.

Utilizando apenas os recursos materiais e humanos disponíveis, sem o dispêndio de recursos financeiros, a Ouvidoria do SLU conseguiu mudar em curto prazo a filosofia de transparência, controle e tratamento das demandas dos usuários do Serviço de Limpeza Urbana do Distrito Federal. O trabalho almejado buscava desenvolver plano anual de ação, com a definição de boas práticas, revisão das atribuições regimentais, desenvolvimento de fluxos, procedimentos, manual e lista de verificação, instalação do sistema nas unidades operacionais, disseminação da importância da Ouvidoria, da transparência e das demandas do usuário.

A metodologia de Gestão por Resultados foi escolhida pela equipe para otimizar os trabalhos da Ouvidoria do SLU e é altamente replicável. Apesar da simplicidade, é comprovadamente eficiente e eficaz. Entretanto, não basta apenas a metodologia, é preciso haver o envolvimento do triângulo do sucesso: Direção, Ouvidoria e áreas técnicas. A participação ativa da Presidência, Diretorias e do corpo técnico do SLU foram cruciais para as mudanças circunstanciais que beneficiaram os 
usuários da limpeza urbana no Distrito Federal. Destacam-se as características-chave de sucesso para a Gestão por Resultado na Ouvidoria do SLU:

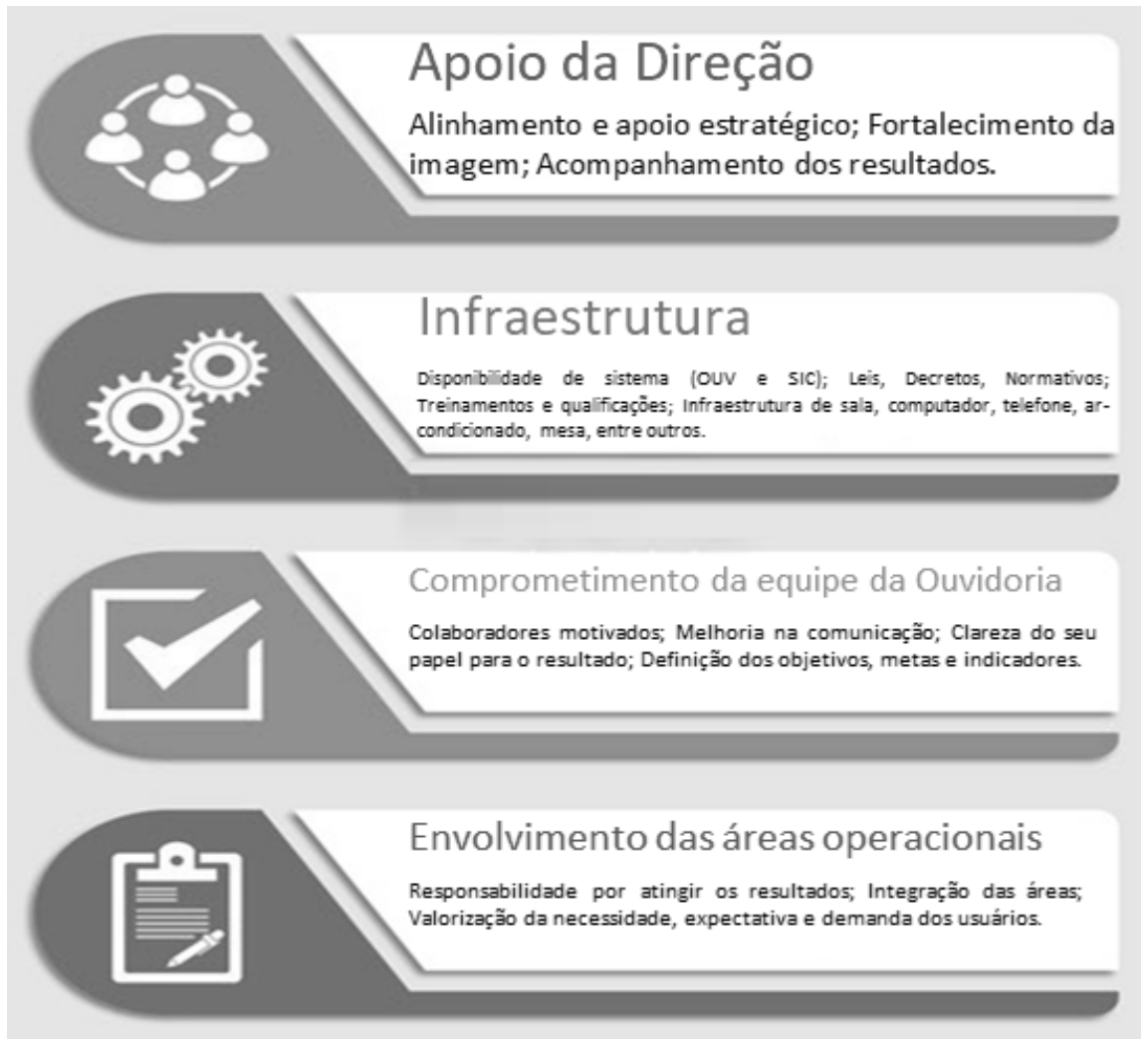

Os resultados alcançados com a adoção da presente metodologia foram:

Benefícios aos processos: Parceria e reconhecimento interno (ambiente cada vez mais cooperativo entre servidores públicos do SLU, em favor da Ouvidoria e com a qualidade dos serviços/ produtos ofertados); melhoria circunstancial dos indicadores de atendimento; melhora no ambiente de trabalho e no espaço de atendimento e melhora no processo de tratamento das demandas (desburocratização).

Benefícios aos usuários: Valorização das demandas dos usuários; transparência nos atos da instituição (índice de transparência ativa e passiva); melhora no tempo e na qualidade da resposta; extinção de respostas desconectadas das demandas; redução do barulho na coleta de lixo; disponibilidade da Carta de Serviços aos usuários; percepção e avaliação positiva sobre o serviço de limpeza urbana no Distrito Federal (pesquisa de opinião dos serviços prestados); participação cidadã, com o Conselho de Limpeza Urbana (Conlurb).

Em 2015, a Ouvidoria do SLU era a 9a Ouvidoria do GDF mais acionada. Já em 2018, as demandas do SLU não representam nem $2 \%$ do volume total de manifestações da rede ${ }^{4}$. Ferramentas

4 Ver Ouvidoria-Geral do Distrito Federal em Referências. 
simples de gestão e o envolvimento de todos geram resultados poderosos aos usuários.

Comprova-se que inovação é a capacidade de transformar a equipe, as atribuições e os processos em resultados para os usuários. Sendo assim, o trabalho é inovador pelo posicionamento da Ouvidoria como unidade consultiva na melhoria dos produtos e serviços.

A resposta ao usuário não é o único trabalho da Ouvidoria. Todo atendimento gera um banco de dados importante sobre o qual o Ouvidor deve trabalhar e utilizar como instrumento, para que o gestor da instituição adote medidas que elevem o padrão de qualidade dos serviços de limpeza urbana, buscando a melhoria contínua. Para esse alcance, a Ouvidoria não pode e nem deve se restringir à sala de trabalho. Tanto o Ouvidor quanto sua equipe devem se ambientar com todos da instituição, conhecer os processos e seus gargalos.

Por fim, o processo de fortalecimento e de empoderamento da Ouvidoria é longo e exige várias ações. A Ouvidoria é um espaço estratégico de participação dos beneficiários, uma vez que busca exatamente analisar, consolidar e recomendar ajustes nas políticas públicas de limpeza urbana determinadas pelo Governo com base nas escutas, contribuições, reclamações e sugestões exaradas pelos usuários.

Agradecimentos aos colaboradores: Barbara, Carlos, Ellen, Ester, Gildete, Isadora, Janaina, Jessica, Maria Senhora, Maria Socorro, Marlúcia, Matheus, Mayara, Paulo Henrique, Rosimeire, Tânia e Valdete. E aos gestores: Félix, Kátia, Paulo Celso, Reis e Silvano.

\section{REFERÊNCIAS}

BARREIRO, Adriana Alvim; PEREZ, José Roberto; PASSONI, Eric (Org.). Construindo a Ouvidoria no Brasil: avanços e perspectivas. São Paulo: Ed. Unicamp, 2011. p. 36.

CAMPOS, Heliana Kátia Tavares. Como fechamos o segundo maior lixão do mundo. Disponível em: http://www. assecor.org.br/files/3015/4470/2872/como_fechamos_o_segundo_maior_lix_o_do_mundo_.pdf. Acessado em: 28 maio 2018.

CARDOSO, Antônio Semeraro Rito; MENEZES, Ronald do Amaral. Ouvidoria pública brasileira: reflexões, avanços e desafios. 1. ed. Brasília - DF: Ipea, 2016.

DICIONÁRIO AURÉLIO. Disponível em: https://www.dicio.com.br/relatorio/. Acesso em: 28 maio 2019.

DRUCKER, P. The Practice of Management. New York: Harper and Row, 1954.

ENAP - Escola Nacional de Administração Pública. Análise e Melhoria de Processos Metodologia MASP, Brasília, 2015.

GOMES, Eduardo Granha Magalhães. Gestão por resultados e eficiência na Administração Pública: uma análise à luz da experiência de Minas Gerais. São Paulo: EAESP/FGV, 2009.

JURAN, Joseph M. Quality Planning And Analysis. New York: McGraw-Hill, 1993.

OUVIDORIA-GERAL do Distrito Federal. Disponível em: http://www.ouvidoria.df.gov.br/desempenho-da-ogdf-em-2018-mostra-excelentes-resultados/. Acesso em: 28 maio 2019.

. Disponível em: http://www.ouvidoria.df.gov.br/sistema-ouv-df-premiado/. Acesso em: 28 maio 2019.

OXFORD ENGLISH DICTIONARY. Disponível em: https://www.oed.com/. Acesso em: 28 maio 2019.

RIBEIRO, Érica Bezerra Queiroz. Aplicação da Lei de Acesso à Informação na Administração Pública Federal. 2. ed. Brasília-DF: Ministério da Transparência, 2016.

WATSON, Gregory H. Benchmarking estratégico. São Paulo: Makron Books, 1994. 